\title{
Dynamic expression of the main related indicators of thrombosis, inflammatory reaction and tissue damage in a rat model of myocardial infarction
}

\author{
MEI XUE, HUIJUN YIN, LU ZHANG, CHUNYU GUO, YUERONG JIANG, \\ CAIFENG WU, XUEFENG LI and KEJI CHEN \\ Department of Cardiovascular Disease, Xiyuan Hospital, \\ China Academy of Chinese Medical Sciences, Beijing 100091, P.R. China
}

Received January 25, 2011; Accepted April 19, 2011

DOI: $10.3892 / \mathrm{mmr} .2011 .485$

\begin{abstract}
In this study, the dynamic expression of granule membrane protein-140 (GMP-140), tissue-type plasminogen activator (t-PA), high-sensitivity C-reactive protein (hs-CRP), interleukin (IL)-6, matrix metalloproteinase (MMP)-9 and tissue inhibitor of metalloproteinase (TIMP)-1 was observed in a rat model of myocardial infarction. Out of 276 Wistar rats, 6 were randomly selected as the control group, and the rest were randomly divided into 18 groups, with 15 rats in each group. The left coronary artery was ligated in 9 groups to establish the myocardial infarction model, and the remaining 9 groups served as the sham-operated groups without ligature. Of the surviving rats, 6 were randomly selected from each myocardial infarction group and shamoperated group, respectively, at 6, 12, 18, 24 and $36 \mathrm{~h}$, and at 2, 3, 5 and 7 days after successful modeling. Serum levels of GMP-140, t-PA, hs-CRP, IL-6, MMP-9 and TIMP-1 were then detected using an enzyme-linked immunoassay. The results revealed that, after successful modeling, the serum levels of GMP-140 and MMP-9 continually increased, reaching the first peak at $18 \mathrm{~h}$ and the maximum peak on day 2. Levels then decreased slightly, but remained higher than those of the control group $(\mathrm{p}<0.05)$. The serum levels of hs-CRP and IL-6 increased, reached a peak at $18 \mathrm{~h}$, and then decreased slightly, but were still significantly higher than those of the control group $(\mathrm{p}<0.05)$. The serum level of $t-P A$ decreased significantly $(\mathrm{p}<0.05)$ and was restored to baseline by day 5 . The serum level of TIMP-1 started to decrease as of $24 \mathrm{~h}$, but was maintained until day $7(\mathrm{p}<0.05)$. In conclusion, in a rat model of myocardial infarction, the thrombosis, inflammatory reaction and tissue damage-related indicators GMP-140, hs-CRP, IL-6 and MMP-9 increased significantly, while t-PA
\end{abstract}

Correspondence to: Dr Huijun Yin, Department of Cardiovascular Disease, Xiyuan Hospital, China Academy of Chinese Medical Sciences, Beijing 100091, P.R. China

E-mail: huijunyin@yahoo.com.cn

Key words: thrombosis, inflammatory reaction, tissue damage and TIMP-1 decreased dynamically. Based on the dynamic changes of each indicator, the optimal intervention time may be determined.

\section{Introduction}

Granule membrane protein-140 (GMP-140), tissue-type plasminogen activator (t-PA), high-sensitivity C-reactive protein (hs-CRP), interleukin (IL)-6, matrix metalloproteinase (MMP)-9 and tissue inhibitors of metalloproteinase (TIMP)-1 play a significant role in the occurrence and development of acute myocardial infarction (AMI) as the main related indicators of thrombosis, inflammatory reaction and tissue damage (1-7). For example, previous reports have revealed that GMP-140 reaches its peak expression only $24 \mathrm{~h}$ after AMI attack (8). However, although the dynamic changes of these related indicators have been extremely significant in helping to determine medication and blood sampling time, there are few studies detailing these changes in the acute phase of AMI. Therefore, the present study aimed to evaluate dynamic changes in GMP-140, t-PA, hs-CRP, IL-6, MMP-9 and TIMP-1 in a rat model of AMI.

\section{Materials and methods}

Experimental protocol. A total of 276 male Wistar rats weighing 180-200 $\mathrm{g}$ were purchased from the Institute of Laboratory Animal Sciences, Chinese Academy of Medical Sciences. The protocol was approved by the animal care and ethics committee of the China Academy of Chinese Medical Sciences. The control group comprised 6 randomly selected rats, and the remainder were randomly divided into 18 groups, with 15 rats in each group. The left coronary artery was ligated in 9 of the 18 groups to establish the AMI model according to Olivetti's methods $(9,10)$. The rats were anesthetized by intraperitoneal injection of urethane solution (20\%) at a dose of $0.6 \mathrm{ml} / \mathrm{kg}$. The rats in the remaining 9 groups were shamoperated, and did not undergo ligation. Of the surviving rats, 6 were randomly selected from each myocardial infarction and sham-operated group at 6, 12, 18, 24 and $36 \mathrm{~h}$, and at 2, 3, 5 and 7 days after successful modeling. Blood (4-5 ml) was 


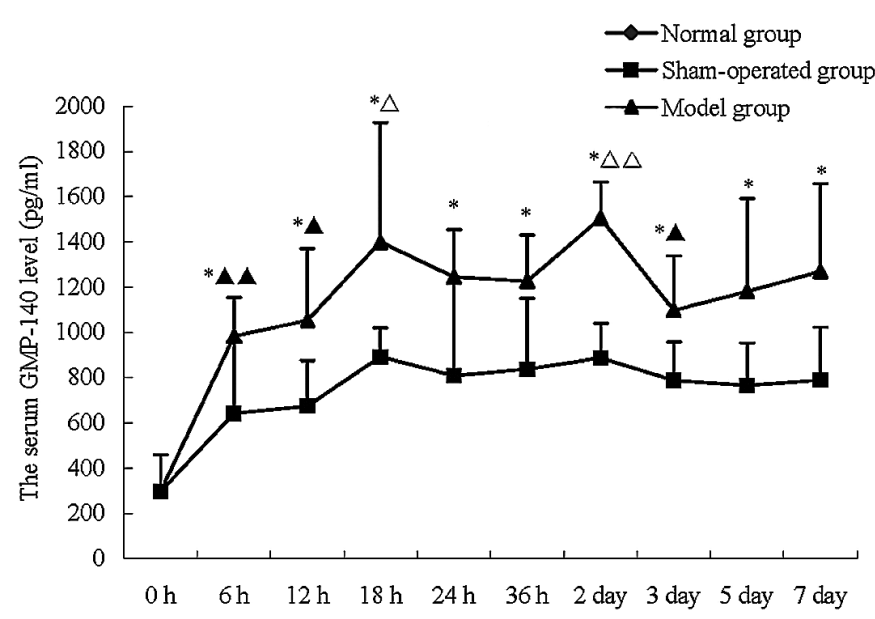

Figure 1. Dynamic changes in serum GMP-140 at various time points. ${ }^{*} \mathrm{p}<0.05,{ }^{* *} \mathrm{p}<0.01$ compared to the sham-operated group; ${ }^{\circ} \mathrm{p}<0.05,{ }^{\Delta \Delta} \mathrm{p}<0.01$ compared to the $6 \mathrm{~h}$ model group; ${ }^{\wedge} \mathrm{p}<0.05,{ }^{\Delta} \mathrm{p}<0.01$ compared to the day 2 model group. Data are expressed as the mean \pm SD.

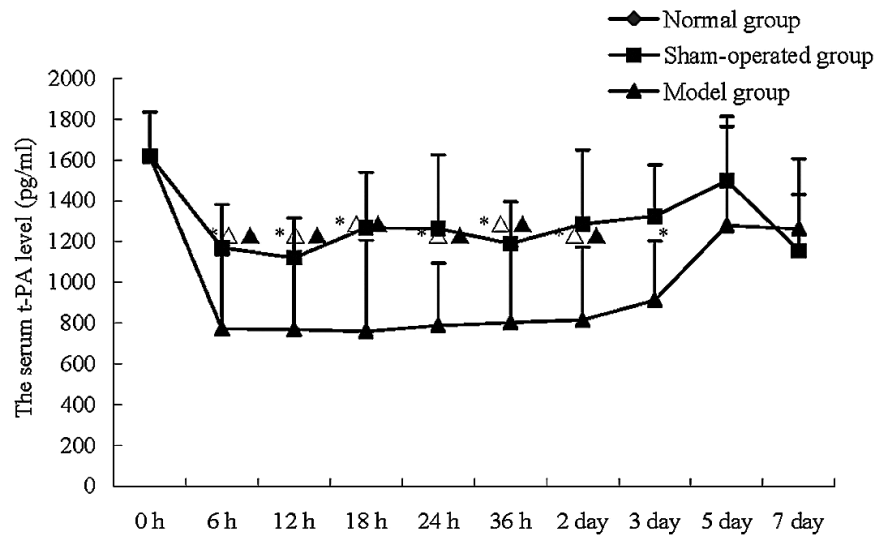

Figure 2. Dynamic changes in serum t-PA at various time points. ${ }^{*} \mathrm{p}<0.05$, ${ }^{* *} \mathrm{p}<0.01$ compared to the sham-operated group; ${ }^{\circ} \mathrm{p}<0.05,{ }^{\triangle}{ }^{\triangle} \mathrm{p}<0.01$ compared to the 5 day model group; ${ }^{\wedge} \mathrm{p}<0.05,{ }^{\Delta} \mathrm{p}<0.01$ compared to the day 7 model group. Data are expressed as the mean \pm SD.

drawn from the abdominal aorta after anesthetization with $20 \%$ urethane solution, and was centrifuged at 2,000 rpm for $15 \mathrm{~min}$. The serum was collected and preserved at $-20^{\circ} \mathrm{C}$ for further analysis.

Enzyme-linked immunosorbent assay. The serum levels of GMP-140, t-PA, hs-CRP, IL-6, MMP-9 and TIMP-1 were detected using an enzyme-linked immunosorbent assay (ELISA) according to the manufacturer's instructions. The ELISA kit, GMP-140, t-PA, hs-CRP, IL-6, MMP-9 and TIMP-1 were all provided by R\&D Systems Co. (USA), subpackaged by Shanghai Boatman Biological Technology Co. Ltd. A Multiskan type 3 microplate reader (Thermo Scientific) was used for detection.

Statistical analysis. Data are presented as the mean \pm SD. The student's t-test was used for the measurement of paired group data. The general linear model was used for comparison of the same index at various time points. $\mathrm{p}<0.05$ was considered statistically significant.

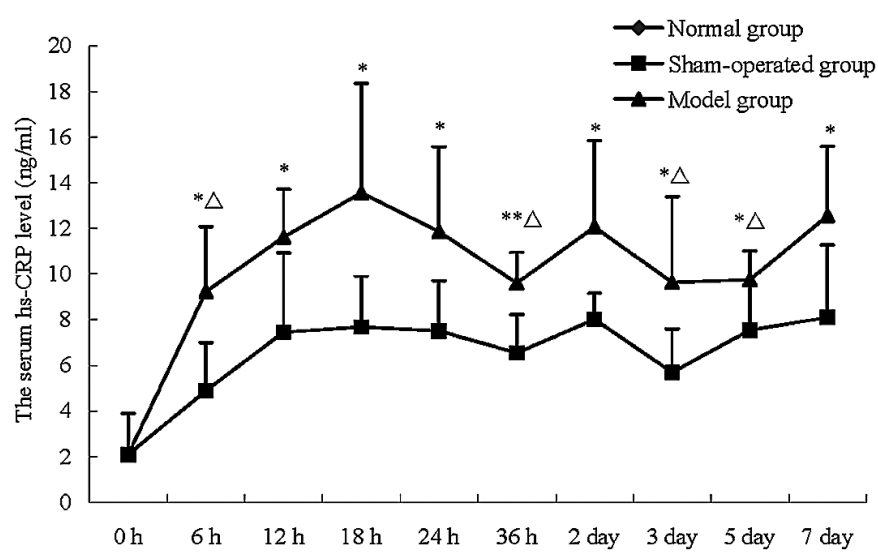

Figure 3. Dynamic changes in serum hs-CRP at various time points. ${ }^{*} \mathrm{p}<0.05$, ${ }^{* *} \mathrm{p}<0.01$ compared to the sham-operated group; ${ }^{\triangle} \mathrm{p}<0.05,{ }^{\Delta \Delta} \mathrm{p}<0.01$ compared to the $18 \mathrm{~h}$ model group. Data are expressed as the mean $\pm \mathrm{SD}$.

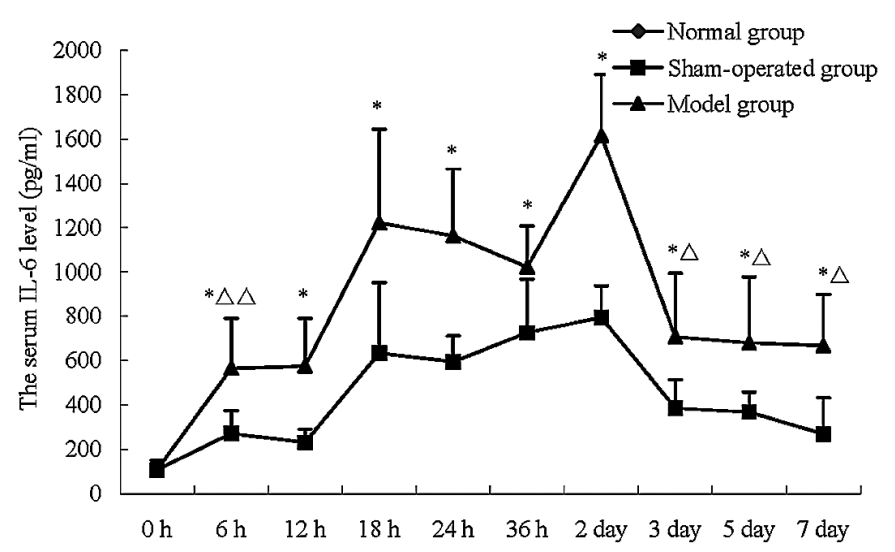

Figure 4. Dynamic changes in serum IL-6 at various time points. ${ }^{*} \mathrm{p}<0.05$, ${ }^{* *} \mathrm{p}<0.01$ compared to the sham-operated group; ${ }^{\triangle} \mathrm{p}<0.05,{ }^{\triangle} \mathrm{p}<0.01$ compared to the 18,24 and $36 \mathrm{~h}$ and day 2 model groups. Data are expressed as the mean $\pm \mathrm{SD}$.

\section{Results}

\section{Thrombosis-related indicators}

Dynamic changes in serum GMP-14. The serum GMP-140 levels were significantly increased at various time points in the model groups compared to the sham-operated groups $(\mathrm{p}<0.05$, $\mathrm{p}<0.01$ ) (Fig. 1). The serum GMP-140 levels were higher in the $6 \mathrm{~h}$ to day 7 model groups compared to the control group, higher in the $18 \mathrm{~h}$ and day 2 model groups compared to the $6 \mathrm{~h}$ group $(\mathrm{p}<0.05, \mathrm{p}<0.01)$, and higher in the day 2 model group compared to the $12 \mathrm{~h}$ and day 3 model groups $(\mathrm{p}<0.05$, $\mathrm{p}<0.01)$. Differences at other time points were not significant $(\mathrm{p}<0.05)$. The serum GMP-140 levels continually increased, reaching their first peak at $18 \mathrm{~h}$ and the maximum peak at day 2 . They then decreased slightly, but remained higher than those of the control group.

Dynamic changes in serum $t-P A$. The serum t-PA levels were significantly decreased in the $6 \mathrm{~h}$ to day 3 model groups compared to the sham-operated groups $(\mathrm{p}<0.05)$ (Fig. 2) The serum t-PA levels were lower in the $6 \mathrm{~h}$ to day 3 model groups compared to the control group. However, in the day 5 and day 7 model groups $(\mathrm{p}<0.05)$ they were increased, though without significance compared to the control group $(\mathrm{p}<0.05)$. 


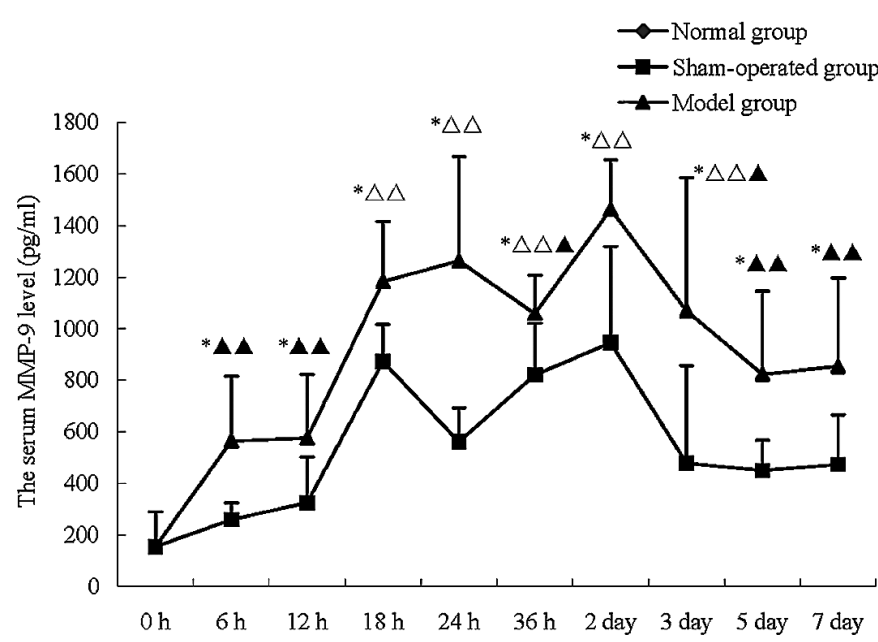

Figure 5. Dynamic changes in serum MMP-9 at various time points. ${ }^{*} \mathrm{p}<0.05$, ${ }^{* *} \mathrm{p}<0.01$ compared to the sham-operated group; ${ }^{\circ} \mathrm{p}<0.05,{ }^{\triangle \Delta} \mathrm{p}<0.01$ compared to the 6 and $12 \mathrm{~h}$ model groups; ${ }^{\mathrm{s}} \mathrm{p}<0.05,{ }^{\mathbf{\Delta}} \mathrm{p}<0.01$ compared to the day 2 model group. Data are expressed as the mean $\pm \mathrm{SD}$.

The serum t-PA levels significantly decreased and were restored to baseline by day 5 .

\section{Inflammatory reaction-related indicators}

Dynamic changes in serum hs-CRP. The serum hs-CRP levels were significantly increased at various time points in the model groups compared to the sham-operated groups $(\mathrm{p}<0.05, \mathrm{p}<0.01)$ (Fig. 3). The serum hs-CRP levels were higher in the $6 \mathrm{~h}$ to day 7 model groups compared to the control group, and higher in the $18 \mathrm{~h}$ model group compared to the 6 and $36 \mathrm{~h}$, day 3 and day 5 model groups, respectively $(\mathrm{p}<0.05)$. Differences in comparison to the remaining model groups were not significant $(\mathrm{p}<0.05)$. The serum hs-CRP levels continually increased and reached their first peak at $18 \mathrm{~h}$. They then decreased slightly, but remained higher than those of the control group.

Dynamic changes in serum IL-6. The serum IL-6 levels were significantly increased at various time points in the model groups compared to the sham-operated groups $(\mathrm{p}<0.05$, $\mathrm{p}<0.01$ ) (Fig. 4). The serum IL-6 levels were higher in the $6 \mathrm{~h}$ to day 7 model groups compared to the control group, and higher in the 18, 24 and $36 \mathrm{~h}$ and day 2 model groups compared to the $6 \mathrm{~h}$, day 3 , day 5 and day 7 model groups $(\mathrm{p}<0.05, \mathrm{p}<0.01)$. Differences in comparison to the remaining model groups were not significant $(\mathrm{p}<0.05)$. The serum IL-6 levels continually increased and reached their first peak at $18 \mathrm{~h}$. They began to decrease after day 3 , but remained higher than those of the control group.

\section{Tissue damage-related indicators}

Dynamic changes in serum MMP-9. The serum MMP-9 levels were significantly increased at various time points in the model groups compared to the sham-operated groups $(\mathrm{p}<0.05, \mathrm{p}<0.01)$ (Fig. 5). The serum MMP-9 levels were higher in the $6 \mathrm{~h}$ to day 7 model groups compared to the control group, significantly higher in the 18,24 and $36 \mathrm{~h}$, day 2 and day 3 model groups compared to the 6 and $12 \mathrm{~h}$ model groups $(\mathrm{p}<0.01)$, and significantly higher in the day 2 model group compared to the 6,12 and $36 \mathrm{~h}$, and day 3 , day 5 and

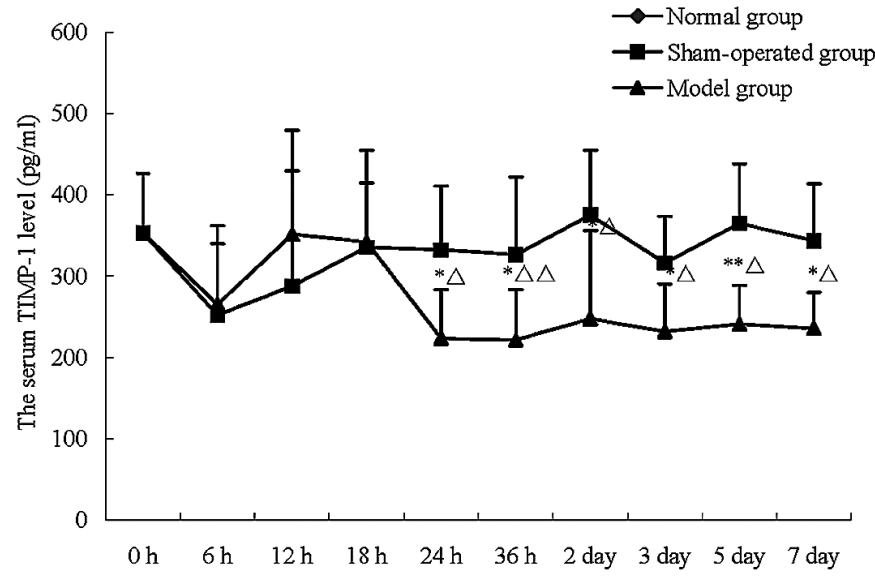

Figure 6. Dynamic changes in serum TIMP-1 at various time points. ${ }^{*} \mathrm{p}<0.05$, ${ }^{* *} \mathrm{p}<0.01$ compared to the sham-operated group; ${ }^{\circ} \mathrm{p}<0.05,{ }^{\Delta} \mathrm{p}<0.01$ compared to the control group. Data are expressed as the mean $\pm \mathrm{SD}$.

day 7 model groups, respectively $(\mathrm{p}<0.05, \mathrm{p}<0.01)$. The serum MMP-9 levels continually increased, reaching their first peak at $18 \mathrm{~h}$ and the maximum peak on day 2 . They then decreased slightly, but remained higher than those of the control group.

Dynamic changes in serum TIMP-1. The serum TIMP-1 levels were significantly decreased in the $24 \mathrm{~h}$ to day 7 model groups compared to the sham-operated groups $(\mathrm{p}<0.05$, $\mathrm{p}<0.01$ ) (Fig. 6), and were significantly decreased in the $24 \mathrm{~h}$ to day 7 model groups compared to the control group $(\mathrm{p}<0.05$, $\mathrm{p}<0.01)$. The serum TIMP-1 levels started to decrease as of $24 \mathrm{~h}$, but were maintained until day 7 .

\section{Discussion}

Coronary atherosclerotic plaque rupture and subsequent thrombogenesis may lead to acute occlusion of the coronary arteries, which is the most predominant cause of AMI. Currently, anti-coagulation and anti-platelet therapy are essential treatments for the clinical prevention of re-occlusion of coronary thrombosis (11). GMP-140, as a member of the selectin family, is only expressed on the degranulated platelet surface. As a marker of late-phase platelet activation and one of the specific indicators presently known to most directly reflect the degree of platelet activation (12), it is closely correlated with thrombosis. A clinical study noted GMP-140 levels to be increased as of $12 \mathrm{~h}$ after AMI attack, reaching a peak on day 2 (8). In this study, the serum GMP-140 level in the AMI rats continued to increase $6 \mathrm{~h}$ after successful modeling, reaching the first peak at $18 \mathrm{~h}$ and the maximum peak on day 2 . It then decreased slightly, although it remained increased compared to the control group. After the successful modeling of AMI, the blood vessels became occluded and the vessel wall was injured, causing platelet aggregation, fibrin deposition and thrombosis. Meanwhile, the t-PAmediated fibrolysis system was also initiated. Serum t-PA levels significantly decreased, potentially due to their having been exhausted by the activation of the fibrolysis system, which may further promote the occurrence and development of thrombosis. The t-PA levels were restored to baseline levels by day 5. A study on balloon injury to the rabbit iliac artery by More et al (13) also found that t-PA activation was 
markedly decreased $2 \mathrm{~h}$ after surgery, and remained at a lower level until returning to control group levels 7 days after surgery.

Inflammatory reaction, the main cause of the occurrence and development of atherosclerosis, is one of the primary factors behind the occurrence of AMI (14). hs-CRP is capable of reliably predicting the risk of cardiovascular diseases. IL-6, with its extensive bioactivities, causes various biological effects in the process of inflammatory reaction, anti-infection and injury $(15,16)$. The serum levels of hs-CRP and IL- 6 were increased in the successfully modeled rats, reaching a peak at $18 \mathrm{~h}$. Afterwards, the serum hs-CRP level decreased somewhat, while the serum IL-6 level did not begin to decrease until day 3. The levels of hs-CRP and IL-6 were increased compared to the control group. The expression of the cytokines GMP-140, t-PA, hs-CRP and IL-6 was significantly increased $6 \mathrm{~h}$ after AMI, indicating that platelet activation, fibrolysis and blood clotting system activation, as well as a tissue inflammatory reaction, jointly participated in the process after AMI. Of these, t-PA, which participates in the activation of fibrolysis and the blood clotting system, was the first to be restored to baseline levels, while platelet activation and inflammatory reaction continued throughout the acute phase of MI.

AMI may induce ventricular remodeling. It manifests not only as pachyntic and necrotic myocardial cells, thickening of coronary vessels and insufficient growth of capillaries, but also in the destruction of the dynamic equilibrium between the synthesis and degradation of collagen fibers, which further results in impaired heart function and the occurrence of heart failure. MMP is the main enzyme system to degrade the extracellular matrix. TIMP is the endogenous specific inhibitor of MMP. In this study, serum MMP-9 levels began to increase $6 \mathrm{~h}$ after AMI, reaching the first peak after $18 \mathrm{~h}$ and the maximum peak by day 2 . They then decreased slightly, but remained higher than those of the control group. Serum TIMP-1 levels started to decrease $24 \mathrm{~h}$ after successful modeling, but were maintained until day 7. MMP-9 was observed to participate in the reconstitution that occurred in the first several hours to several days after AMI, while changes in the serum TIMP-1 levels lagged slightly behind those of MMP-9. When the relative balance between serum MMP-9 and TIMP-1 is not maintained, it may aggravate tissue damage and the process of ventricular remodeling (17).

Previous studies have revealed that tissue plasminogen activator antigens can be used to predict the occurrence of cardiovascular events after AMI (18), while the fibrolysis and blood clotting system, as well as the metalloproteinases, jointly participate in the pathophysiological process of left ventricular remodeling after AMI (19). In this study, the expression of t-PA and MMP-9 was increased compared to the control group during the early phase of AMI after successful modeling of rat myocardial infarction.

In conclusion, changes in thrombosis, inflammatory reaction, and tissue damage indicators were observed for 7 days after AMI. Based on the dynamic changes of each indicator, the optimal intervention time may be determined. This provides fundamental reference data for experimental studies. In future studies, more time points will be added and analyzed, and indices such as heart function will be combined.

\section{Acknowledgements}

This study was supported by the National Basic Research Program of China (grant no. 2006CB504803).

\section{References}

1. Yip HK, Chang LT, Sun CK, et al: Platelet activity is a biomarker of cardiac necrosis and predictive of untoward clinical outcomes in patients with acute myocardial infarction undergoing primary coronary stenting. Circ J 70: 31-36, 2006.

2. Liu WH, Yang CH, Yeh KH, et al: Circulating levels of soluble P-selectin in patients in the early and recent phases of myocardial infarction. Chang Gung Med J 28: 613-620, 2005.

3. Ganti AK, Potti A and Yegnanarayan R: Plasma tissue plasminogen activator and plasminogen activator inhibitor-1 levels in acute myocardial infarction. Pathophysiol Haemost Thromb 32: 80-84, 2002.

4. Bian Y, Chen YG, Xu F, Xue L, Ji WQ and Zhang Y: The polymorphism in aldehyde dehydrogenase- 2 gene is associated with elevated plasma levels of high-sensitivity C-reactive protein in the early phase of myocardial infarction. Tohoku J Exp Med 221: 107-112, 2010.

5. Kang WQ, Song DL and Guo XG: Relationship between serum vasoactive factors and plaque morphology in patients with acute coronary syndrome. Zhonghua Xin Xue Guan Bing Za Zhi (in Chinese) 35: 1020-1023, 2007.

6. Miyazaki S, Kasai T, Miyauchi K, et al: Changes of matrix metalloproteinase-9 level is associated with left ventricular remodeling following acute myocardial infarction among patients treated with trandolapril, valsartan or both. Circ J 74: 1158-1164, 2010.

7. Dinh W, Füth R, Scheffold T, et al: Increased serum levels of tissue inhibitor of metalloproteinase-1 in patients with acute myocardial infarction. Int Heart J 50: 421-431, 2009.

8. He Y, Shen W, Zhao Y, Yang X, Shao B and Yuan C: The dynamic changes of platelet P-selectin and glycoprotein $\mathrm{V}$ in acute myocardial infarction. Suzhou University of Medical Science (in Chinese) 26: 777-779, 2006.

9. Abbate A, Salloum FN, Vecile E, et al: Anakinra, a recombinant human interleukin-1 receptor antagonist, inhibits apoptosis in experimental myocardial infarction. Circulation 117: 2670-2683, 2008.

10. Olivetti G, Capasso JM, Meggs LG, Sonnenblick EH and Anversa P: Cellular basis of chronic ventricular remodeling after myocardial infarction in rats. Cir Res 68: 856-869, 1991.

11. Chen Z and Gao R: Coronary heart disease. People's Medical Publishing House, Beijing, pp879-882, 2003.

12. Chen KJ, Xue M and Yin HJ: The relationship between platelet activation and coronary heart disease and blood-stasis syndrome. J Capit Med Univ 29: 266-269, 2008.

13. More RS, Underwood MJ, Brack MJ, De Bono DP and Gershlick AH: Changes in vessel wall plasminogen activator activity and smooth muscle cell proliferation and activation after arterial injury. Cardiovasuclar Res 29: 22-26, 1995.

14. Napoleão P, Santos MC, Selas M, Viegas-Crespo AM, Pinheiro T and Ferreira RC: Variations in inflammatory markers in acute myocardial infarction: a longitudinal study. Rev Port Cardiol 26: 1357-1363, 2007.

15. Kishimoto T: Interleukin-6: from basic science to medicine -40 years in immunology. Annu Rev Immunol 23: 21, 2005.

16. Ding C, Cicuttini F, Li J and Jones G: Targeting IL-6 in the treatment of inflammatory and autoimmune diseases. Expert Opin Investig Drugs 18: 1457-1466, 2009.

17. Kelly D, Squire IB, Khan SQ, et al: Usefulness of plasma tissue inhibitors of metalloproteinases as markers of prognosis after acute myocardial infarction. Am J Cardiol 106: 477-482, 2010.

18. Lowe GD, Danesh J, Lewington S, et al: Tissue plasminogen activator antigen and coronary heart disease. Prospective study and meta-analysis. Eur Heart J 25: 252-259, 2004.

19. Weir RA, Balmain S, Steedman T, et al: Tissue plasminogen activator antigen predicts medium-term left ventricular endsystolic volume after acute myocardial infarction. J Thromb Thrombolysis 29: 421-428, 2010. 